\title{
OS 50 ANOS DA PÓS-GRADUAÇÃO EM DIREITO DA USP \\ NA VISÃO DE UM EX-ALUNO, ATUAL PROFESSOR \\ E EX-COORDENADOR
}

José Eduardo Faria ${ }^{1}$

Nestes tempos de instabilidade, desorientação, indignação e ressurgimento de formas explícitas ou difusas de fascismo e autoritarismo, em que a democracia representativa parece revelar-se como um sistema cujas instituições e valores não conseguem absorver a insegurança e garantir a estabilidade, o aniversário de 50 anos da criação do curso de pós-graduação stricto senso da Faculdade de Direito da Universidade de São Paulo pode ser visto, na perspectiva de um sociólogo e teórico do direito a partir de diferentes acontecimentos.

$\mathrm{Na}$ qualidade de antigo aluno, atual professor e ex-coordenador desse curso, destaco quatro ocorrências:

a) Em primeiro lugar, a criação desse curso não foi precedida por um diagnóstico da pós-graduação do Brasil nem pela formulação de um projeto pedagógico. A exemplo do que ocorrera após a reforma universitária de 1968 imposta pelo regime militar, quando os departamentos da Faculdade de Direito foram montados a partir da aglutinação de cátedras conexas, garantindo com isso o prestígio e a força decisória dos catedráticos, a pós-graduação da Faculdade de Direito foi tão mal concebida que seus responsáveis não perceberam que não criaram um único curso com dezenas de disciplinas encadeadas de modo orgânico. Na realidade, criaram um curso de pós-graduação por departamento. ${ }^{2}$

Como eram nove departamentos, foram criados nove cursos, sem qualquer encadeamento orgânico entre as disciplinas. E, como não podia ser diferente, não havia um recorte de campo temático, nem definição de linhas de pesquisa nem, muito menos, algumas disciplinas obrigatórias, especialmente em termos de metodologia de pesquisa. O que, por consequência, impediu, durante anos, que a pós-graduação da Faculdade de Direito da USP escola desse um passo além dos estudos meramente dogmáticos e produzisse teses de doutorado que alargassem a fronteira do conhecimento jurídico.

1 Professor titular da Faculdade de Direito da Universidade de São Paulo. Chefe do Departamento de Filosofia e Teoria Geral do Direito. Ex-coordenador da Comissão de Pós-Graduação em Direito da USP.

2 A primeira vez em que ouvi comentários críticos sobre esse equívoco de concepção da pós-graduação em direito na USDP foi numa mesa redonda que coordenei para o Jornal da Tarde e para O Estado de S. Paulo, na primeira metade dos anos de 1970, com a presença dos professores Roque Spencer Maciel de Barros e Newton Sucupira. Coordenei outras entrevistas com eles mais tarde, quando as mesmas observações foram, mais numa vez, feitas em off. 
b) O resultado foi tão desastroso que, oito anos depois, ao avaliar o nível de qualidade dos cursos de pós-graduação em direito em todo o país, com especial ênfase para os cursos criados por universidades públicas no Rio de Janeiro e São Paulo, o Conselho Nacional de Desenvolvimento Científico e Tecnológico (CNPq) fez graves advertências em sucessivos relatórios.

Nesse sentido, basta ver o relatório de 1978, de cuja preparação participei, em minha primeira experiência como assessor de uma agência de fomento à pesquisa. "A teoria jurídica precisa acompanhar o desenvolvimento sócio-econômico (...), mas o que tem feito é trabalhar com categorias tradicionais, modelos fechados, visões formalistas e soluções abstratas. O Direito transformou-se num mero instrumento casuístico do poder (autoritário) e pragmaticamente dirigido para remover obstáculos". 3

De certo modo, isso já havia sido dito de modo até mais enfático por uma consultoria sobre o ensino do direito no Brasil encomendada pela Ford Foundation no início da década de 1970 a um filósofo do direito, Henry Steiner, de Harvard, a um cientista social, Robert Packenhan, de Stanford, e a um sociólogo do direito, David Trubek, então em Harvard e, mais tarde, a grande liderança intelectual da renovação do ensino jurídico americano, a partir de sua base na Wisconsin Law School. Depois de ter conversas com Packnham e Steiner sobre seus trabalhos, trabalharia na década seguinte quase um ano com Trubek. Entre os três, havia um consenso no sentido de que o peso excessivo do formalismo estéril nos cursos jurídicos brasileiros decorria da "visualização do direito como um sistema estático em lugar de um processo de adaptação das normas aos fatos e necessidades em mudança. O estudante deve(ria) perceber a mudança através de uma série de instantâneos de um dado campo do direito. Mas o real processo de mudança, seus meios e problemas de adaptação ao sistema jurídico comumente escapam à análise", dizia Steiner. "As normas são estudadas não só fora do seu contexto histórico e social, mas também divorciadas de suas matrizes institucionais e processos de mudança dentro do sistema jurídico. A lei é identificada quase que exclusivamente como o conteúdo normativo do sistema jurídico" -

Esse argumento traduz o que foi discutido sobre a mesma questão num importante seminário realizado meses antes da elaboração do relatório do CNPq, organizado pela Universidade Federal de Santa Maria. O evento hoje está esquecido, mas foi importante - entre outros motivos teve a participação de integrantes do comitê da área de direito do CNPq. Um deles foi Joaquim Falcão. Durante sua intervenção, que foi documentada pela Associação Latinoamericana de Metodologia do Ensino do direito, ele pergunta a quem interessa e contra o que e contra quem é a reforma do ensino jurídico. Sua resposta: "Na medida em que em nosso país o Estado controla a maior parte dos recursos. E legisla sobre todas as nuances do ensino jurídico, a reforma não é apenas um affaire de professores e estudantes, juristas e sociólogos. É sobretudo uma tarefa do Estado, e como tal antes de ser um problema didático, ou jurídico teórico, a reforma do ensino é um problema político". 
concluía, depois de também lembrar que o currículo da graduação e da pós-graduação não abrangia temas e assuntos de grande importância. ${ }^{4}$

Datado de 1982 e também influenciado pelos pareceres de Steiner, Trubek e Packnham, o relatório seguinte do CNPq mantinha o mesmo tom crítico e contundente do severo relatório de área de 1978. Uma passagem do texto, particularmente, merece ser transcrita, por ser uma espécie de denominador comum de todas as análises, estudos e relatórios daquele período. "O desempenho da pós-graduação e da pesquisa está longe de corresponder ao que deles esperam a comunidade científica e o mercado de trabalho. Na medida em que as faculdades de direito se encontram fechadas à pesquisa jurídica, seja ela científica ou não, o país começa(rá) a criar outros órgãos geradores do conhecimento jurídico". 5

Na mesma época, a Coordenadoria de Aperfeiçoamento de Pessoal de Nível Superior (Capes) publicou documento na mesma linha das críticas do CNPq. O texto afirmava que os programas da pós-graduação em direito no país, inclusive o da USP, não eram elaborados com sólidos suportes metodológicos, nem, muito menos, demonstravam que os bolsistas tinham exata informação sobre o universo, o objetivo e as fontes da pesquisa jurídica em que suas investigações deveriam se apoiar. E dizia, ainda, que as sugestões e orientações feitas pelo CNPq no relatório de 1978 continuavam sendo ignoradas ou desconhecidas pelos coordenadores dos cursos de pós-graduação em direito. ${ }^{6}$

c) Nesse meio tempo, enquanto CNPq e Capes passaram a pressionar a Faculdade de Direito da USP a regularizar sua pós-graduação stricto senso, reduzindo de nove cursos para um único, com definição de linha de pesquisa, com recorte temático e com explicitação de seu suporte metodológico, surgiu outro problema não menos complicado e importante. Paralelamente ao curso que ora completa 50 anos de existência,

${ }_{4}$ Cf. Henry Steiner, Tradições e tensões na educação jurídica abrasileira: um estudo sobre a mudança socioeconômica, Cadernos da PUC/RJ, Rio de Janeiro, PUC/RJ, Divisão de Intercâmbio, Caderno n. 17, 1974, pp.69-70.

5 Esses relatórios constam do acervo do $\mathrm{CNPq}$ e, durante muitos anos, foram objeto de seminários da disciplina de Metodologia do Ensino e da Ciência do Direito criada entre 1983 e 1984 pelo professor Tércio Sampaio Ferraz Jr. e por mim, e que é oferecida até hoje, sob minha responsabilidade. Evidentemente, o programa mudou ao longo do tempo, valorizava a formação histórica da metodologia científica, o ensino do direito como atividade metódica, e métodos de raciocínio jurídico. Hoje, entre outros itens, discute o estatuto epistemológico das ciências humanas e da ciência do direito e o lugar da história no pensamento jurídico, exame as possibilidades de interação entre os papéis da dogmática e da crítica jurídica e enfatiza a necessidade de mudanças no ensino do direito a partir da substituição do monismo jurídico pelo pluralismo jurídico e o impacto da aceleração do processo schumpeteriano de destruição criadora no direito público e privado. Para uma análise desses e dos demais relatórios tanto do CNPq quanto da Coordenação de Aperfeiçoamento de Pessoal de Ensino Superior (Capes), ver Aurélio Wander Bastos, Pesquisa Jurídica no Brasil: diagnóstico e perspectivas, Revista Sequência: estudos jurídicos e políticos, Florianópolis, n. 23, dezembro de 1991, p. 11-24.

6 Ver Aurélio Wander Bastos, op. cit., p.13. 
a escola mantinha um curso de pós-graduação lato senso que fora criado antes do stricto senso e da reforma universitária.

Era um curso pessimamente desenhado, sem um mínimo de coerência na oferta de disciplinas e sem efetivo envolvimento dos professores que nele lecionavam. À época, era relativamente pequeno o número de professores doutores que atuavam na pós-graduação estrito e lato senso. Sobrecarregados e/ou desmotivados, a maioria dos livres docentes e titulares (alguns dos quais eram antigos catedráticos) deu preferência à pós-graduação estrito senso, que lhes assegurava mais prestígio. Com isso, a pós lato senso foi praticamente largada, com poucas disciplinas oferecidas e sem cobrança de trabalhos de conclusão de curso.

Embora tivessem uma formação não mais do que sofrível e não tivessem conseguido passar no exame seletivo da pós stricto senso, queixavam-se de eram pouquíssimas as disciplinas oferecidas e exigiam que a faculdade lhes desse um certificado de conclusão de curso. À medida que livre-docentes e titulares deixavam de lecionar na pós-graduação lato senso, os alunos não podiam concluir os créditos e com isso exigir o certificado, porque as disciplinas oferecidas não eram suficientes para que pudessem atender a todas as exigências.

Foi quando, recém-saído de minha livre-docência, recebi o convite dos docentes que integravam a Comissão de Pós-Graduação, convite esse intermediado pelo professor Geraldo de Camargo Vidigal, para assumir o controle do lato senso. E a proposta que me foi feita era no sentido não de reformá-lo mas, isto sim, de estudar um caminho para simplesmente extingui-lo, mesmo sob o risco de tensões e protestos. Evidentemente, por razões legais ele não podia ser fechado do dia para noite. E, fracos ou não, os alunos tinham direitos adquiridos e a faculdade tinha a obrigação legal e moral de permitir que eles concluíssem o curso. Ou seja, o pedido foi que gerisse o fim dessa obrigação, o que me obrigou a oferecer disciplinas que assegurassem aos alunos os créditos faltantes.

d) Não me lembro com exatidão quanto tempo durou esse processo de fechamento daquele curso de pós-graduação lato senso. Contudo, a experiência que acumulei naquela tarefa, conjugada com o fato de que também assumira a coordenação do Grupo de Trabalho sobre Direito e Sociedade, na Associação Nacional de Pós-Graduação em Ciências Sociais (ANPOCS), deu-me deu o mix necessário de conhecimento, prudência e horizonte para assumir, alguns anos depois, a presidência da Comissão de Pós-Graduação (CPG), por indicação de um professor de processo civil, José Ignácio de Botelho Mesquita, e outro de direito do trabalho, Octávio Bueno Magano. Ambos lideravam os debates na comissão, mas divergiam em vários aspectos. Depois de muita polêmica, chegaram à conclusão de que estavam prejudicando o órgão. E concordaram que ele deveria ser presidido por um docente da geração da mais nova, anterior à deles. E, 
num surpreendente consenso, apontaram meu nome. Ao mesmo tempo, essa era também uma solução natural, pois já vinha sendo relator dos casos mais difíceis, a pedido de ambos. Passei pouco mais de seis anos na CPG, os quais quatro na chefia.

Minha primeira preocupação foi afirmar aos colegas que uma instituição acadêmica de ponta, como é o caso da Faculdade de Direito da USP, não depende apenas de instalações tomadas pelo patrimônio histórico, mas, acima de tudo, da força de sua dimensão imaterial e simbólica. E isso depende de sua inserção na sociedade e da coerência de sua trajetória ao longo do tempo. O que me levou a fazer essa afirmação foi a consciência de que a hegemonia de um pensamento doutrinário quase único, baseado no formalismo e na dogmática jurídica, seria incapaz de oferecer ao alunado da pós a dimensão do que ocorria num país com acentuada a mobilidade social e então atingido por fortes transformações econômicas, políticas e culturais.

Minha segunda preocupação foi chamar atenção dos colegas de CPG e da representação discente para a importância de um pluralismo não apenas teórico, mas igualmente, metodológico, sem o que não teríamos diálogo acadêmico e a formação de uma massa crítica capaz de alargar o horizonte acadêmico da pós-graduação. Em outras palavras, o desafio foi apontar o risco da hegemonia de uma linha de pensamento basicamente monodisciplinar - no caso o formalismo de cariz kelseniano - de compelir o curso de pós-graduação rumo a discussões estéreis sobre questões banais e triviais. A uma perda de tempo e recursos públicos com questões pouco relevantes, notadamente no debate sobre o que é o direito e seu objeto e sobre os limites do conhecimento jurídico, desprezando com isso os problemas da eficácia do direito numa sociedade altamente desigual e conflitiva. E, também, inviabilizando a conversão de reivindicações sociais, de problemas econômicos e questões culturais concretas em desafios teóricos e metodológicos. E, por fim, circunscrevendo o valor justiça, convertendo-o num simples problema de validez formal da ordem jurídica.

A estratégia era persuadir os colegas da CPG de que precisávamos, primeiramente, sair de um mundo imaginário que a maioria dos orientadores da pós stricto senso então ensinava, como se vivesse numa sociedade bem estruturada, equilibrada e justa. E, em segundo lugar, compreender os diferentes fenômenos que, à época, vinham levando a sucessivas ondas de explosão de litigiosidade. Os seis anos em que atuei na CPG foram, basicamente, entre 1990 e 2000. Nesse período, os litígios judiciais mais do que duplicaram. O país passou de 5,1 milhões de novos conflitos ajuizados em 1990 nas justiças estadual, federal e trabalhista, para cerca de 12,2 milhões, no exercício de 2000, seja por causa do advento de novos litigantes, como movimentos e organizações não-governamentais, seja pela multiplicação dos conflitos de massa envolvendo concessionárias de serviços públicos, magazines e redes de varejo, principalmente após a estabilização da moeda propiciada pelo Plano Real. 
O legado mais visível de minha gestão foi a mudança radical na prova de qualificação, que até então envolvia apenas um a redação a partir do sorteio de dez pontos de cada área de concentração. Era uma exigência inútil, sem o menor sentido pedagógico, uma vez que era a repetição de uma prova idêntica à do processo seletivo para ingresso na pós. Foi justamente aí que se implantou o sistema hoje vigor, que pressupõe uma banca examinadora integrada pelo orientador e por dois docentes convidados, que leem o projeto, fazem crítica, oferecem sugestões. Com isso, não apenas abrem novas perspectivas para os mestrandos e doutorandos, como também fazem uma espécie de controle de qualidade das orientações - ou seja, todos ganham. O legado menos visível de minha gestão, mas que teve enormes custos políticos, foi resistir no Conselho de PósGraduação a uma pressão no sentido de substituir o modelo intelectual que sempre norteou a pós-graduação stricto sendo da USP, por um modelo de caráter gerencial que, por ser apegado a uma visão utilitária do saber, defendia para as dissertações e teses um recorte temático mais pragmático, voltado seja para o mercado de trabalho dos pós-graduandos, seja para atender os interesses da iniciativa privada. Era um modelo que descaracterizava por completo a ideia de universidade pública num país em desenvolvimento.

A ciência do direito e a erosão de seus modelos cognitivos

Por que me refiro a essas quatro ocorrências, num texto sobre o aniversário de 50 anos da pós-graduação da Faculdade de Direito da USP? O motivo é simples: porque elas refletem, de modo singelo e impressionista, o que senti como aluno e hoje sinto como professor e antigo coordenador desse curso. A saber: o mundo jurídico, de um modo geral, e o ensino jurídico brasileiro, mais especificamente, encontrou-se ao longo desse meio século crescentemente marcado pela erosão de seus modelos cognitivos. Falo de modelos forjados no século 19 e na transição para o século 20, quando eram outras as condições econômicas, sociais, políticas e culturais do país e do mundo.

Tendo participado da redação de alguns relatórios dos comitês de área das agências de fomento à pesquisa na década anterior à de minha ascensão à CPG e também integrando naquele momento o grupo que coordenava a área de ciências humanas da Fundação de Amparo à Pesquisa do Estado de São Paulo (Fapesp), estava ciente disso. Tinha consciência de que "o advogado é mais um prisioneiro que senhor do direito", como dizia Henry Steiner, ${ }^{7}$ quando afirmava que as faculdades brasileiras de direito não preparavam adequadamente os estudantes para o raciocínio analítico, lógico e analógico; não exigiam agilidade mental e nem estimulavam uma formação crítica e independente.

Cf. Henry Steiner, Tradições e tensões na educação jurídica brasileira: um estudo sobre a mudança socioeconômica e legal, op. cit. p.67-68. 
A cada relatório, ia me convencendo de que o problema do ensino jurídico estava na ênfase excessiva que a dogmática jurídica dava às relações internas do sistema legal, em vez de se debruçar sobre o inter-relacionamento daquele sistema com a sociedade. Ia aprendendo que, no caso de minha faculdade, que se recusava a sair do centro da cidade e mudar-se para o campus do Butantã, somente a relação da ideia de direito positivo com a vida real, por meio de enforques interdisciplinares, permitiria à pós-graduação stricto da velha escola do Largo São Francisco dar um passo à frente, no alargamento das fronteiras do conhecimento jurídico. Era a forma, imaginava eu, de pôr fim a um certo vazio intelectual como resposta a novos problemas - vazio esse presente em todos cursos de pós-graduação da área.

Além disso, pela experiência acumulada tanto nos comitês de área das agências de fomento à pesquisa quanto como avaliador in loco de alguns cursos de universidades públicas e privadas, em nome da Capes, conscientizara-me de outro problema. A profunda crise de identidade então vivida pelas faculdades de direito de todo o país, dado seu excessivo apego ao formalismo e ao legalismo implícitos no pensamento kelseniano, segundo o qual os juristas trabalham com o sentido jurídico nas normas de direito positivo, e não com os fatos em si. Desse modo, a ciência do direito seria uma ciência do sentido das normas jurídicas - normas que proíbem, facultam ou impõem.

Dito de outro modo, o ensino do direito não envolveria o ensino de um saber a respeito do mundo tal como ele de fato é, com suas fraturas, com suas circunstâncias e contingências, com seus riscos e suas incertezas. ${ }^{8}$ Envolveria, sim, um saber acerca de normas capazes de determinar o que se deve e não se pode fazer. Decorre daí a crise de identidade a que me refiro. Afinal, de um lado abordagens como essa são basicamente profissionalizantes e acríticas. De outro lado, contudo, as faculdades de direito - quer na graduação quer na pós-graduação - devem ser, por princípio, questionadoras e problematizantes. Tendo trabalhado 37 anos consecutivos com um dos filhos de Júlio de Mesquita Filho, o filho do homem que criou a Universidade de São Paulo, sabia que essa dimensão interrogativa estava no DNA da instituição em que fui aluno e hoje sou decano.

A ideia de risco se contrapõe à ideia de incerteza, que se refere a situações em que não é possível conhecer as probabilidades e desfechos futuros relevantes, ou seja, em que é impossível ter qualquer presunção. A distinção entre risco (com probabilidade mensurável) e incerteza (que não pode ser medida) foi apontada pelo economista americano Frank Night, em Risco, incerteza e lucro, Rio de Janeiro, Editora Expressão e Cultura, 1972. A obra original é de 1921. A distinção é retomada mais tarde por John Maynard Keynes. Em A Teoria geral do Emprego, do Juro e da Moeda, ele afirma que o risco pode ser comprovado por meio da teoria da probabilidade, enquanto a incerteza se basearia apenas em estimativas subjetivas. $\mathrm{O}$ denominador comum do pensamento de ambos é que, nas situações de profunda incerteza, pouco adianta os economistas atribuírem probabilidades arbitrárias a cenários e contextos que advirão de processos inteiramente imprevisíveis. A distinção entre risco e incerteza hoje também vem sendo aprofundada pelos professores que estudam o direito a partir da teoria dos sistemas. 
A pós-graduação da USP em direito e o contexto de seus 50 anos

Com sua força heurística e classificatória, os modelos cognitivos tradicionais no campo do direito - tanto os desenvolvidos pelos privatistas franceses da transição para o século 20 quanto para os publicistas que encontram em Hans Kelsen seu maior artífice, operavam como verdadeiros mapas. Ou seja, como mecanismos de redução da complexidade, que ajudavam a delimitar espaços, ideia implícita à noção de soberania. A estabelecer hierarquias, ideia implícita à estrutura do Estado de Direito moderno. A definir limites, ideia implícita à noção de liberdades públicas e garantias fundamentais. E a sinalizar metas, ideia implícita à noção de desenvolvimento, correção de desigualdades e promoção de justiça social.

A partir do declínio da era da sociedade delimitada territorialmente e integrada politicamente, por um lado, e do surgimento de redes internacionais de atividades, de conhecimento e de poder, na esteira do processo disruptivo das novas tecnologias de comunicação e do desenvolvimento de plataformas digitais, por outro lado, aumentou a circulação de ideias, mercadorias e capitais, deflagrando grandes transformações sociais, econômicas e políticas. Entre outras consequências, essas transformações levaram os poderes hierarquizados e soberanias absolutas a ceder lugar a sociedades mais horizontais, pluralistas e multiculturais. E, com isso, a política se deslocou da autoridade direta para a conexão comunicativa, da hierarquia para a heterarquia, da heteronomia para a autonomia.

Por essas razões, vivemos hoje em um período marcado pela tensão entre inovações técnicas e científicas e analfabetismo de valores cívicos. Em m contextos em que as referências tradicionais entraram em colapso; em que não conseguimos mais compreender o sujeito e o mundo como realidades dadas e como processo; em que as instituições estatais e sociais atravessam por uma profunda crise de autoridade, de identidade política e de sobrecarga sistêmica; em que o aumento do conhecimento científico e do saber técnico tem, como desdobramento paradoxal, o aumento do conhecimento $^{9}$ e, por consequência, da insegurança, do medo e das contingências sociais.

Nesse cenário, mais precisamente no período correspondente aos 50 anos da pós-graduação stricto senso da Faculdade de Direito da USP, as teorias do direito tradicionais perderam a capacidade de responder algumas questões fundamentais. Entre essas questões, destaco seis:

(a) como justificar a violência em casos de necessidade e como definir a agressão injusta?

9 Cf. Daniel Innerarity, La democracia del conocimiento: por uma sociedade inteligente. Barcelona: Paidós, 2011, especialmente o capítulo $3^{\circ}$ (La sociedade del conocimiento y la ignorancia). 
(b) como avaliar as consequências de acontecimentos sem modelos cognitivos que nos ajudem a entendê-los?

(c) como interpretar acontecimentos que provocam rupturas, bifurcações e perturbações na ordem vigente?

(d) como, num contexto de descontinuidades, incertezas e instabilidade, de que modo lidar com mudanças intensas e radicais se nossos esquemas cognitivos no direito foram concebidos para tempos "normais", ou seja, de estabilidade e continuidade?

(e) como lidar com as mudanças nas relações entre tempo e espaço em períodos de erosão da política e de emergência de diferentes temporalidades?

(f) se os direitos de que alguns desfrutam não se generalizam para todos, não estamos então falando de privilégios - e não de direitos?

Uma vez que a pós-graduação brasileira no campo do direito não se revelou capaz de alargar as fronteiras do conhecimento, conforme os já mencionados relatórios do CNPq das décadas de 1970 e seguintes, não surgiram há respostas consistentes e coerentes a essas indagações. Quando muito, foram oferecidas somente respostas anômalas, no sentido de Thomas Kuhn dá ao termo. ${ }^{10}$ Com isso, o Direito e as teorias jurídicas do século 20 passaram do status de ciência condutora - aquela que catalisa o alargamento das fronteiras do conhecimento em suas diferentes áreas - para o de ciência conduzida, aquela que não consegue se renovar nos planos teórico e metodológico.

A sociologia do direito na pós-graduação em direito da USP

Coincidindo na USP com as duas primeiras décadas do curso de pósgraduação em direito, a introdução da sociologia do direito na graduação, inicialmente, e na própria pós, mais tarde, surgiu marcada pela confrontação com a ciência do direito - mais precisamente, como reação ao formalismo, ao legalismo e ao dogmatismo dominantes ao longo século 20. Por princípio, em sua origem a sociologia do direito é anti-formalista, interdisciplinar e sensível à perspectiva socioeconômica e sociocultural

10 Kuhn define o paradigma como uma matriz disciplinar e afirma que ciência progride quando os cientistas são treinados numa tradução intelectual comum, usando-a para ver os problemas que ela própria suscita. A matriz disciplinar consiste em 4 elementos: a) generalizações simbólicas; b) pressupostos metafísicos; c) valores; d) soluções para problemas concretos. Os modelos considerados exemplares são os de soluções de problemas-padrão. Servem como guia para questões reais. As generalizações simbólicas são esboços de leis, interpretadas com apoio de pressupostos que não são testados empiricamente. As fases normais das ciências são aquelas em que a matriz disciplinar fornece os limites dos problemas, os próprios problemas e suas respostas. As fases revolucionárias são aquelas em que os paradigmas entram em crise. O acúmulo de anomalias leva os cientistas a buscar alternativas. As ciências imaturas não têm paradigmas formados, A tese de Kuhn é no sentido de que a nova e a antiga teoria são incomensuráveis em dois aspectos: a) usam os mesmos termos com sentidos diferentes e (b) os exemplares também são diferentes, motivo pelo qual os cientistas acabam observando fatos diversos. Ver KUHN, Thomas. A estrutura das Revoluções Cientificas. São Paulo, 1997. A versão original data de 1962. 
do direito. Reivindicando sua autonomia epistemológica e seu estatuto científico e acadêmico, a sociologia do direito priorizou a questão das correspondências entre as sociedades e seus sistemas jurídicos. No século 19, Marx, com sua abordagem dialética, já descrevera o direito como instrumento de dominação da burguesia e poder monárquico. Por outro lado, na transição do século 19 para o século 20, Durkheim, com seu método funcionalista, enfatizou as correlações entre formas de solidariedade (mecânica/orgânica) e as formas de direito (penal/cooperativo). E Weber, com sua sociologia compreensiva, apontou os processos de organização do conhecimento de tipo secular, de racionalização formal e de burocratização após o Renascimento, enfatizando, como consequência, a juridificação da sociedade moderna.

Esses três autores são decisivos na formação da sociologia do direito. Nas suas vertentes originárias, a da Jurisprudência de Interesses e a do movimento do Direito Livre, o que então se valoriza é uma maior flexibilidade nos mecanismos de funcionamento dos sistemas jurídicos. O que se tem a partir daí são reflexões e análises sensíveis:

(a) a uma concepção pluralista de direito e de suas fontes de produção;

(b) a uma concepção sociológica de uma ciência do direito e a uma recusa da lógica dedutiva e das metodologias descritivo-positivistas;

(c) a uma aproximação com o realismo americano e escandinavo;

(d) à crítica das construções formais e à resposta à tese kelseniana de que a sociologia do direito, por ter caráter instrumental, seria uma ciência menor.

Quatro são os denominadores comuns dessas reflexões e análises:

(a) a tensão entre a perspectiva interna e a perspectiva externa do direito, isto é, a tensão entre uma sociologia do direito dos juristas e uma sociologia do direito dos sociólogos;

(b) a questionável autodefinição do sociólogo do direito como observador objetivo, que somente descreve os fatos;

(c) o dogma da radical separação entre o âmbito do ser e o âmbito do dever ser, com a subsequente crítica dos juristas aos sociólogos, por limitarem seu olhar somente à faticidade;

(d) a negação à sociologia do direito da possibilidade de formalizar seu objeto de conhecimento, o que a tornaria uma ciência auxiliar da ciência do direito.

No período de sua afirmação e institucionalização, a sociologia do direito enfatiza as dimensões epistemológicas, históricas, teóricas e sistemáticas da reflexão jurídica. Ao descortinar novos horizontes para a reflexão teórica e a interpretação da realidade social, ela se concentra em novos objetos e temas, tais como eficácia do direito, democratização no acesso ao Judiciário, luta por novos direitos e identificação das tensões estruturais nas relações entre direito e economia, entre direito e planejamento 
e direito e finanças públicas, com forte influência de autores funcionalistas forjados na tradição de Weber e Parsons. ${ }^{11}$

Os riscos sofridos pela sociologia do direito nesse período, e que ela teve dificuldades para afastá-los em certo momento, foram;

(a) excesso de abertura à interdisciplinariedade, que pode desfigurar a sociologia do direito como disciplina epistemologicamente autônoma;

(b) em princípio, o trabalho interdisciplinar é efêmero, uma vez que depende da existência de pessoas formadas em disciplinas bem definidas que, em determinados momentos, buscam formas de conhecimento e cooperação com pessoas de outra área;

(c) o foco excessivo na empiria desprezaria o fato de que os fatos do direito não se apresentam de forma bruta, na realidade socioeconômica; são fatos "construídos" mediante um processo de interações entre o objeto do conhecimento e o sujeito cognoscente, em que o caráter jurídico da facticidade do direito não pode ser visto exclusivamente em termos de ação social e organização social.

Os movimentos críticos do direito

No final da década de 1960 e no decorrer da década de 1970, quando surgem e se expandem nos Estados Unidos e na Europa movimentos como Law and Development, Law and Society, Law and Economics e os Critical Legal Studies, a sociologia do direito tem como contraponto a guerra fria, o conflito no Vietnã, a rebelião estudantil de maio de 68 e a emergência das ditaduras latino-americanas, o que leva uma sociologia do direito avalorativa, acrítica e descritiva a ceder vez para uma sociologia do direito como sociologia da contestação.

Já na década de 1980, a sociologia do direito tem como contraponto a transição do autoritarismo para a democracia na América Latina, da social-democracia para o liberalismo nos Estados Unidos e Europa e da ideia de planejamento como mecanismo de construção do futuro para políticas pró-mercado. Isso pode ser visto, com clareza, nas discussões relativas à ideia de legitimidade, bem sistematizadas pelos tradicionais Archives de Philosophie du Droit, editado pela Dalloz, e pelos Archives de Philosophie Politique, editados pela PUF, dos quais a Faculdade de Direito da USP era assinante. E, também,

11 Ver, nesse sentido, Ralf Dahrendorf, Max Weber and modern social science, in Max Weber and his contemporanies, Wolfgand J. Mommnsen e Jürgen OIsterhammel orgs. Londres: Unwin Hyman, 1987; Talcott Parsons. A estrutura da ação social. Petrópolis: Vozes, 2010, v. 2 (a versão original data de 1937); David Easton, A Framework for Political Analysis, Englewood Cliffs: Prentice-Hall, 1965, e Systems Analysis of Political Life. New York: Wiley, 1965; Gabriel Almond. A Discipline Divided: Schools and Sects in Political Science. New York: Sage, 1990. 
pela apresentação de sociólogos do direito vinculados à teoria dos sistemas, como Niklas Luhmann, e filósofos da escola de Frankfurt, como Jürgen Habermas. ${ }^{12}$

Essas discussões se desdobram em quatro direções:

a) definição das regras do jogo como legitimidade a priori, fundindo-se assim os conceitos de legalidade e legitimidade (herança kelseniana);

b) a ideia de legitimação pelo procedimento: regras e decisões podem tornar-se aceitáveis para os interessados desde que sua elaboração se faça através de um processo formalizado; procedimentos são visos como mecanismo de simplificação e redução de incertezas (herança luhmanniana);

c) a vinculação da ideia de legitimidade a processos crítico-deliberativos: não é só o formalismo dos procedimentos que conforma a legitimidade de uma regra, mas, isto sim, o fato desse procedimento ser permeável a discursos morais e depender da participação dos interessados e da igualdade de posição dos locutores no debate púbico (herança habermasiana);

d) legitimação pelos resultados - ideia fortemente explorada pelos governos autoritários latino-americanos nas décadas de 1960 e 1970 (herança de Carl Schmitt). ${ }^{13}$

Essa sociologia do direito mais crítica é fortemente expandida entre as décadas de 1980 e 2000 com base em autores de origens e tendência distintas, como

12 A apresentação de Niklas Luhmann ao universo acadêmico brasileiro no campo do direito se deve, especialmente, a Tércio Sampaio Ferraz Jr, na metade da década de 1980, quando incluiu em sala disciplina de pós-graduação na USP e na PUC a leitura de alguns textos do professor de Bielefeld. Em 1990, Miguel Reale, quando foi homenageado com um seminário obra por sua aposentadoria na USP, convidou Luhmann para participar de um seminário em João Pessoa. Creio que essa viagem, em que teve o filósofo argentino Luís Alberto Warat e eu como guias, foi a única que fez ao Brasil. A partir daí, a presença da teoria dos sistemas cresceu significativamente na área da filosofia, teoria e sociologia do direito em todo o país, especialmente na USP, especialmente por influência de Tércio, num primeiro momento, e dos professores Celso Fernandes Campilongo, em seguida, e Orlando Villas Boas Filho, mais tarde. Quanto a Habermas, seu trabalho passou a ser conhecido no Rio de Janeiro graças às traduções de seus principais livros pela editora Tempo Brasileiro, de Eduardo Portella, e, em São Paulo, graças ao Centro Brasileiro de Análise e Planejamento (Cebrap). Lembro-me de ter assistido uma palestra de Habermas no Instituto Goethe ao lado de um dos fundadores da entidade, José Arthur Giannotti, com quem trabalhava na Comissão de Reforma da Universidade, e que travou com ele um debate acirrado e extremamente interessante.

13 Para Carl Schmitt, autor que influenciou publicistas altamente conservadores no Brasil, e cujas ideias estão presentes nos preâmbulos dos Atos Institucionais n. 1 e n. 5 do regime militar brasileiro, baixados em 1964 e 1968, respectivamente, afirmava que todo o direito, todas as normas e leis, todas as interpretações de leis, todos os ordenamentos são substancialmente decisões do soberano, e soberano não é um monarca legítimo ou uma instância competente, mas exatamente aquele que decide como soberano. "O direito é a lei e a lei é o comando que decide sobre controvérsias em torno do direito", dizia ele. A ideia de "decisionismo" jurídico, teoria segundo a qual o fundamento último do direito é uma decisão política do soberano", a ele associada, foi recebida acriticamente e utilizada por juristas que serviram a regimes autoritários no país. Uma das principais análises críticas do decisionismo jurídico, uma exceção no ambiente acadêmico da área de direito, foi feita por Ronaldo Porto Macedo Júnior, professor do Departamento de Filosofia e Teoria Geral do Direito. Do autor, ver O decisionismo jurídico de Carl Schmitt, in Lua Nova, São Paulo, 1994, n. 32, e Carl Schmitt e a fundamentação do direito. São Paulo: Max Limonad, 2001. 
Michel Foucault, Pierre Bourdieu, Luís Alberto Warat, Duncan Kennedy e outros, abrindo caminho para o interacionismo simbólico, para a fenomenologia, para epistemologias construtivistas e compreensivas e para a análise de sistemas, primeiramente. E para movimentos como Legal Consciousness Studies, Critical Race Theory e Legal Feminism, num segundo momento. ${ }^{14}$ Naquelas décadas, partia-se da ideia de que, mesmo nos chamados casos fáceis, a interpretação jurídica estava marcada por tensões entre valores opostos que não podiam ser equacionados de modo coerente pelo sistema jurídico. Enfatizavam-se reflexões que identificassem as contradições internas do pensamento jurídico e a transformação progressista da sociedade a partir de concepções políticas à esquerda.

A tentativa de desconstrução da cultura jurídica oficial era uma das palavras de ordem à época, sob a justificativa de que ela bloqueava as possibilidades de formular visões alternativas do direito, ao mesmo tempo em que superestimava uma solidez que as instituições jurídicas não tinham no mundo real. $\mathrm{Na}$ área de filosofia, teoria e sociologia jurídica dos cursos de pós-graduação em direito, as discussões eram travadas, nas três primeiras décadas de funcionamento da pós-graduação em direito na USP, com base em três pensadores seminais e então em voga - Michel Foucault, Pierre Bourdieu e Luís Alberto Warat.

De Foucault, por exemplo, valorizava-se a ideia de que o grande jogo da história seria de quem se apoderasse das regras. De quem tomasse o lugar daqueles que as utilizam. De quem se disfarçasse para pervertê-lo, utilizando-as em sentido inverso, voltando-as contra aqueles que as tivessem imposto. Enfim, de quem, introduzindo-se no aparelho complexo, o fizesse funcionar de tal modo que os dominadores se encontrarão dominados por suas próprias regras..$^{15}$

Já com relação a Bourdieu, valorizava-se a noção de violência simbólica de Pierre Bourdieu. ${ }^{16} \mathrm{O}$ direito, dizia ele, resulta de relações de força entre os próprios juristas (ou seja, entre os teóricos e os profissionais da prática jurídica), assim como entre os juristas e seus mandatários (ou seja, entre aqueles que oferecem proteção jurídica e aqueles que precisam dela). Os juristas teóricos tendem a ver o direito como um sistema coerente e a fechá-lo em um racionalismo lógico-formal rígido, enquanto os praticantes do direito se orientam pela casuística de situações particulares concretas,

14 Ver Mauricio Garcia-Villegas. Les pouvoirs du droit: analyse comparée d'études sociopolitiques du droit. Paris: LGDJ, 2015. Ver, igualmente, Duncan Kennedy. Freedom and Constraint in Adjudication: a critical phenomenology. Association of American Law Schools, 1986.

15 Cf. Microfisica do Poder. Rio de Janeiro: Graal, 1979.

16 1979. Dois textos desse autor foram, durante anos, a pièce de resistance dos seminários da disciplina Metodologia do Estudo e da Ciência do Direito: O poder simbólico. Rio de Janeiro: Bertrand Brasil, 1992; e A Reprodução: elementos para uma teoria do sistema de ensino. Lisboa: Editorial Vega, 1978. As versões originais das duas obras são de 1977 e 170, respectivamente. 
renovando o sistema e o adaptando à realidade. Os juristas são responsáveis pela codificação, que cria efeitos de racionalização e universalização, o que faz com que o direito ganhe sua força específica - a violência simbólica. A universalização é um dos fatores mais poderosos da dominação simbólica, ou seja, da imposição da legitimidade de uma ordem social que informa a prática dos agentes. Os juristas são, assim, os guardiões da hipocrisia coletiva. Detêm uma força extremamente grande, mas estão presos no seu próprio jogo.

De Warat, por fim, valorizava-se sua ambiciosa proposta de (a) rever o conceito tradicional da ciência do direito, demonstrando como a partir de um discurso organizado em nome da verdade e da objetividade desvirtuam-se os conflitos sociopolíticos, que se apresentam como relações individuais harmonizáveis pelo direito; (b) questionar as concepções jurisdicistas sobre a lei e a coerção, através das quais são apresentadas as formas jurídicas e estatais como instrumentos de caráter técnico; (c) negar a visão reducionista que apreende o direito como discurso punitivo, moralmente comandado, negligenciando assim a explicação de como as formas jurídicas influenciam na organização de um determinado tipo de relações de produção econômicas, políticas e ideológicas; (d) inverter a razão jurídica dominante, que estabelece uma análise jurisdicista e não política do Estado, a fim de que possamos nos situar, substitutivamente, frente a um discurso que pretende falar politicamente o direito; (e) criar uma consciência participativa que permita aos diferentes juristas engajarem-se nos múltiplos processos decisórios, como fatores de intermediação das demandas da sociedade e não como agentes do Estado. ${ }^{17} \mathrm{O}$ que Warat estimulava, em suma, é uma reflexão sobre as condições para uma nova relação entre técnica jurídica e prática política.

O pensamento jurídico crítico e/ou inovador no século XXI

Esses três autores, contudo, aos poucos foram perdendo espaço no proscênio das discussões jus-sociológicas nas décadas seguintes. A partir da primeira década do século 21, o que se tem é o progressivo declínio da temática por eles privilegiada, como decorrência da internacionalização econômica, da aceleração do processo schumpeteriano de destruição criadora, da reestruturação produtiva da economia capitalista do pós-guerra e da subsequente desterritorialização ou transnacionalização do ensino superior, o que levou a novas fontes de informação, a novas especializações, a

17 Do autor, ver El derecho y su linguaje. Buenos Aires: Cooperadora de Derecho y Ciencias Sociales, 1976; A produção crítica do saber jurídico, in Crítica do Direito e do Estado, Carlos Alberto Plastino org. Rio de Janeiro: Graal, 1984; e Epistemologia e Ensino do Direito: o sonho acabou. Florianópolis: Fundação José Arthur Boiteux, 2004. 
uma maior diferenciação funcional e a novas estruturas de poder econômico e político em diferentes escalas - do local ao global.

O que se tema partir daí é o esgotamento da hierarquia como princípio ordenador da política, com a transterritorialização dos mercados e o advento das novas tecnologias de comunicação. O que também se tem é a sobreposição da ideia de governabilidade à ideia de legitimidade. ${ }^{18} \mathrm{O}$ que se tem, ainda, é a substituição de uma agenda que conjugava crescimento com pleno emprego e inclusão social por uma agenda exclusivamente economicista, que prioriza o princípio da responsabilidade fiscal e a austeridade monetária com base em processos de desconstitucionalização e deslegalização de direitos e privatização de empresas estatais, como estratégia de corte de gastos, neutralização da sobrecarga das demandas sobre o Estado e equilíbrio das finanças públicas.

A partir da primeira década do século 21 , o panorama da sociologia do direito entre nós, reverberando o que acontecia na Europa e nos Estados Unidos, muda com o advento da sociedade da austeridade e das reformas de $1^{\mathrm{a}}$ e $2^{\mathrm{a}}$ gerações propostas pelo Banco Mundial. ${ }^{19}$ Nesse contexto, a tendência da sociologia do direito é de se voltar basicamente a coleta de dados e a estatísticas. Ao mesmo tempo, vão surgindo na teoria jurídica modelos que, de algum modo, atendem às necessidades econômicas de mercados globalizados. Refiro-me ao modelo de Direito Responsivo, de Philip Selznick e Phillippe Nonnet; ao modelo de Direito autopoiético, de Niklas Luhmann; e ao modelo de Direito Reflexivo, de Gunther Teubner, Helmut Willke e Karl Heinz Ladeur.

Selzninck e Nonnet identificaram as mudanças sociais, econômicas e políticas que pressionaram a abertura do direito a novos temas e na direção de novas soluções nas décadas finais do século 20. Mostraram como a resistência a essa abertura por parte dos juristas de formação dogmática, em nome da integridade da ordem legal, levaria à perda de legitimidade e de efetividade das instituições jurídicas. E jogaram luz na transição do direito autônomo, ou seja, a ordem legal-racional, para o chamado direito responsivo, afeito às novas questões e problemas de sociedades complexas. ${ }^{20}$ Luhman, Teubner, Willke e Ladeur ${ }^{21}$ partiram da ideia de que cada esfera dessa sociedade tende a se

18 Ver Chris Thornhill. The Sociology of Law and the Global Transformation of Democracy. Cambridge: Cambridge University Press, 2018.

19 Discuto essas mudanças de modo mais aprofundado em Direito e Conjuntura. São Paulo: Saraiva/FGV, 2009, e O Direito e o Estado depois da crise. São Paulo: Saraiva/FGV, 2013.

20 Dos autores, ver Law and Society in transition: towards a responsive law. New York: Harper and Row, 1979.

21 Dos autores, ver Niklas Luhmann, Law as a social system. Oxford: Oxford University Press, 2004 (a versão original é de 1993); Günther Teubner. Autopoietic law: a new approach to law and society. Berlim/ Nova York: Walter de Gruyter, 1988; Helmult Willke. The tragedy of the State: prolegomena to a Theory of State in polycentric society, Archiv für Rchts und Sozialphilosophie, Stuttgart, 1986, v. 5, n. 6; e Karl-Heniz Ladeur, The financial market crisis - a case of network failure? In: The Financial Crisis in Constitutional 
autorregular e que o Estado e o direito por ele positivado existem apenas para solucionar intervir quando a normatividade produzida em outros sistemas - como o econômico, o financeiro, o científico, o tecnológico e o cultural - se revela ineficaz. Assim, o Estado tende a atuar como mediador ou árbitro intersistêmico, o que acaba levando à erosão do centralismo jurídico.

Independentemente das críticas que possam ser feitas a uma sociologia do direito com preocupação quantitativa e, principalmente, a esses modelos por vezes excessivamente abstratos de caráter funcionalista e sistêmico, o importante é reconhecer que eles tiveram o mérito de apontar:

a) o risco de perversão da democracia, com a redução dos espaços comunicativos e distribuição pouco equitativa das competências argumentativas, por um lado, e de substituição da cidadania cívica por uma cidadania organizacional, por outro;

(b) o risco de emergência de um processo de hiper-responsabilização dos indivíduos com relação ao seu próprio destino, decorrente da ênfase autorregulação, com a subsequente adoção de políticas de sociais focalizadas e tolerância zero;

(c) e o risco de que essa hiper-responsabilização individual acelere a precarização trabalhista e a perda de direitos sociais, aprofundando a exclusão social.

No momento em que a pós-graduação em direito da USP completa 50 anos, período de fortes questionamentos dos valores e formas de vida tradicional e de crescente indeterminação dos marcos políticos, o desafio da sociologia do direito - e, também, da teoria e da filosofia do direito - é recuperar uma análise crítica que, por diferentes razões, os frankfurtianos e os herdeiros dos Critical Legal Studies não teriam aprofundado suficientemente, após a virada do século 20 para o século 21.

No caso específico da pós-graduação em direito no país em termos gerais, e mais particularmente de um projeto para os próximos 50 anos do curso da Faculdade de Direito da USP, em cujo curso orientei mais de 50 mestrandos e doutorandos, o que me seduz, como projeto acadêmico a ser desenvolvido, é estimular as novas gerações a retomar alguns clássicos do pensamento social nacional. E fazê-lo não apenas privilegiando uma vertente saquarema tardia, como é o caso de Oliveira Vianna, ou numa vertente weberiana, como Raymundo Faoro e Victor Nunes Leal, mas, igualmente, numa vertente crítica, sensível às questões do subdesenvolvimento, da dependência e do modelo de industrialização tardia que prevaleceu em quase todo o século 20. Questões essas cujas respostas aproximem a sociedade, onde o que prevalece é a lógica dos fins, das atividades produtivas - que são regidas pela lógica dos meios, como dizia Celso

Perspective: the dark side of functional differentiation. Poul Klaer, Günther Teubner a Alberto Febrajjo orgs. Oxford: Hart Publishing, 2011. 
Furtado, autor cuja leitura me foi recomendada numa conversa de corredor, ao término de uma aula de direito constitucional, pelo professor Manuel Gonçalves Ferreira Filho.

A justificativa para a implantação desse projeto acadêmico, que poderia reunir sociologia, direito público e direito privado, é que ele poderia ser um importante contraponto histórico para a compreensão do alcance da discussão que vem sendo travada entre ultraliberalismo e políticas keynesianas no âmbito da economia, bem como entre transterritorialização dos mercados e negação da integração das economias em escala global, entre soberania nacional e heterarquia, entre monismo e pluralismo jurídico.

Há alguns anos, retomei as leituras de Furtado, que conheci pessoalmente por ser ele colaborador do caderno cultural do Jornal da Tarde, no qual ambos escrevíamos artigos com alguma regularidade, pauteiros, quando preparava um ensaio sobre três brilhantes juristas com formação interdisciplinar e crítica - Raymundo Faoro, Orlando Gomes e San Tiago Dantas. ${ }^{22}$ Este último, colega de Furtado no último governo pré-ditadura militar, era como o economista, um arguto analista da complexidade das funções reguladoras do Estado no capitalismo tardio, das pressões estruturais causadoras da concentração da renda e do desafio de converter crescimento econômico em desenvolvimento social.

E agora, sem entrar na questão relativa à formulação de uma sociologia do direito a partir do Sul-Global, creio ser importante resgatar outros ídolos de minha geração, dos quais destaco Florestam Fernandes, considerado o fundador da sociologia crítica no Brasil. Enfatizo, especialmente, uma palestra que deu nos anos 70, sugestivamente intitulada "a sociologia como contestação", cujo texto - datilografado e em xerox copiei de sua pasta no arquivo do jornal $O$ Estado de S. Paulo. Em sua origem, no período da revolução industrial, dizia ele, a sociologia é uma técnica de autoconsciência e de ação social construtiva. Desenvolvimento implica mudanças estruturais e não se confunde como progresso, como ficou claro na Revolução Industrial. Ele não foi apenas um subproduto da ciência e da inovação tecnológica, mas de sucessivas reconfigurações dos fatores de produção capitalista e da reprodução social burguesa.

Em suas primeiras gerações, afirmava Florestan, sociologia ficou presa a questões metodológicas (como o antagonismo neutralidade vs. subjetividade), o que reduziu suas potencialidades críticas às inovações que mudaram o perfil das relações de produção capitalista e de seu sistema de poder. Apenas quando se libertou dessas discussões e superou a falta de "imaginação sociológica criadora" das correntes conservadoras e liberais, articulando dialeticamente a crise do capitalismo com a emergência do socialismo, é que a sociologia mudou sua agenda. Somente quando passou a enfocar

22 Com o título Juristas fora da curva: três perfis, o ensaio foi publicado pela revista Direito - GV, São Paulo, Fundação Getúlio Vargas, v. 12, n. 2, 2016. 
antagonismos e inconformismos com a ordem vigente, assumindo papel estratégico na configuração de novos padrões civilizatório, é que a sociologia voltou a se reafirmar nas ciências humanas. Em síntese, é preciso formular uma sociologia capaz de influir construtivamente sobre os acontecimentos, a partir da identificação de práticas microrevolucionárias, de novos processos de luta, dizia Florestan. E de pequenas conquistas democráticas, corroendo a hierarquia lógico-formal de dos sistemas jurídicos, digo eu.

Da leitura desse texto de Florestan e de textos de outros cientistas sociais e filósofos que também discutiram o papel da sociologia nesta perspectiva crítica, como Leandro Konder e Carlos Nelson Coutinho (este último meu colega na Comissão de Reforma da Universidade, entre 1985 e 1986), que com ele dialogaram, é possível identificar a atualidade de três importantes pontos do marxismo: (a) a concepção do homem como um ser que se faz a si mesmo pelo trabalho traz com ela a denúncia radical das condições de aviltamento do trabalho, repropondo uma discussão teórico-política a respeito da degradação da criatividade humana, dentro de um sistema que reduz tudo a mercadoria; b) a concepção da história como processo contraditório - no qual os homens dominam as forças da natureza, mas dilaceram a comunidade, lançando os indivíduos e grupos uns contra os outros, na competição pelo lucro - nos estimula a refletir sobre o caminho que tem sido trilhado pelo homem com o objetivo de forjar uma história nova, diferente e mais justa; c) a concepção de ideologia como distorção do conhecimento, decorrente da dilaceração da comunidade humana e do conflito institucionalizado das classes sociais, nos desafia a desconfiar das racionalizações promovidos nos discursos, levando-nos a comparar o que os homens dizem, por um lado, e o que eles realmente fazem, por outro.

Uma nova agenda para a pós-graduação

É nessa perspectiva que a sociologia e a teoria do direito podem e devem pensar numa nova agenda para a pós-graduação em direito do país. Para a formulação dessa agenda, destaco oito pontos, sem a preocupação de pautar todos os desafios que temos pela frente. E, claro, lembrando que eles já foram discutidos por colegas de comitês da área de direito das agências de fomento à pesquisa, como Joaquim Falcão, Bruno Silveira, Mário Machado, Aurélio Wander Bastos, Joaquim Falcão, Luciano de Oliveira e Eliane Junqueira, com os quais partilhamos da amizade com "leading professors", como David Trubek, Andrè-Jean Arnauld, Raffaele de Giorgi, Enrique Zuleta Puceiro e Boaventura de Souza Santos. 
Os pontos são estes:

(a) a concepção da sociedade contemporânea como uma formação complexa na qual se combinam diferentes normatividades, entreabrindo formas conservadoras e progressistas de pluralismo jurídico;

(b) a conversão da ideia de projeto nacional em obstáculo para concepções dominantes de desenvolvimento e governança globais;

(c) a identificação das distintas relações de poder por detrás da distribuição dos custos e benefícios dos fluxos globalizados;

(d) a crítica à aparência de unidade organizacional, do direito, uma vez que o direito positivo conjuga diferentes modos de articulação e instrumentalização;

(e) a ideia de que, se o conhecimento é um instrumento de mobilidade e mudanças, uma vez que gera novas ideias e interpretações que se confrontam com as estruturas vigentes de poder, os centros de pesquisa e os postos na carreira universitária são loci de poder. São, igualmente, loci de controle, já que o princípio da autoridade acadêmica propicia a chancela científica;

(f) essa chancela, para ser realista, precisa basear-se numa avaliação concreta dos meios e recursos disponíveis; para ser científica, exige uma concepção epistemológica sobre a própria ciência; e para ser socialmente relevante, precisa estar sintonizada com os diferentes objetivos da sociedade, enquanto formação complexa, heterogênea e conflitiva; ${ }^{23}$

(g) por fim, a consciência de que a Universidade se encontra espremida entre a lógica racionalizadora do capital e o corporativismo dos diferentes setores que a compõem; e de que seu atrelamento a interesses políticos e corporativos e sua resignação ou subserviência a controles quantitativos de produção acadêmica e a imperativos do mercado, a estão levando a deixar de ser uma instância crítica e a perder sua independência para produzir, aplicar e transmitir conhecimento.

Em suma, comecei dizendo que, quando a pós-graduação da USP foi criada há 50 anos, os modelos cognitivos tradicionais do direito, forjados entre os séculos XIX e XX, operavam como mapas, como mecanismos de redução da complexidade,

23 Cf. Joaquim Falcão, Política cientifica e direito, versão preliminar repassada pelo autor. 
ajudando a delimitar espaços, estabelecer hierarquias, definir limites e sinalizar metas. Meio século depois, num contexto bem mais complexo e marcado por riscos e incertezas, a sociologia e a teoria do direito podem ser decisivas para que o direito deixe de ser uma ciência conduzida e volte a ser uma ciência condutora, como foi entre o final do século XVII e a primeira metade do século XX. Para tanto, contudo, são necessários aprofundamentos teóricos e novas abordagens que nos ajudem a compreender o que ocorre numa sociedade conflitiva, fraturada, perplexa e desorientada, sem incidir na confortável tentação de ocultar sua complexidade e heterogeneidade.

Concluindo, para esses aprofundamentos e para essas abordagens neste período em que diferentes grupos políticos das mais variadas posições políticas tentar impor pautas específicas e tolher o livre debate acadêmico, é preciso fazer, pelo menos, duas advertências. Por um lado, não subestimar as faculdades de Direito como espaço estratégico: numa sociedade cambiante, heterogênea, conflitiva e injusta, como a brasileira, se essas faculdades não produzem o que transmitem ao alunado ou, então, o que transmitem não reflete o conhecimento produzido, sistematizado ou empiricamente identificado, a pesquisa científica está comprometida. Por outro lado, advertir, como têm feito colegas do continente, que é preciso romper a tradição enraizada na América Latina de se inflamar antes de aprofundar o rigor teórico-metodológico.

Se olharmos criticamente para os 50 anos passados, identificando os equívocos que cometemos, o curso de pós-graduação da USP, que é um organismo vivo, certamente chegará ao aniversário de um século de existência com um saldo bastante positivo. 